\title{
Imaging in Fibroid Uterine : A Literature Review
}

\author{
Widiana Ferriastuti ${ }^{\mathrm{a}}$, Lies Mardiyana ${ }^{\mathrm{a}}$, Tri Wulanhandarini ${ }^{\mathrm{a}}$,Andika Suyata ${ }^{\mathrm{b}}{ }$

 \\ ${ }^{a}$ Department of Radiology, Faculty of Medicine, Universitas Airlangga,Jl.Mayjen Prof. Dr. Moestopo No.4-6, Surabaya 60286, \\ ${ }^{b}$ Resident in Department of Radiology, Faculty of Medicine, Universitas Airlangga,Jl.Mayjen Prof. Dr. Moestopo No.4-6, Surabaya \\ 60286,
}

\begin{abstract}
Uterine fibroids, also known as leiomyomas or myomas, are benign (benign) tumours that commonly occur in the uterus. These tumours account for about $20-50 \%$ of gynaecological tumours. Radiological examination plays an important role in diagnosing uterine fibroids. This certainly has implications for the diagnosis, because with this the diagnosis will certainly be sharper and the management of therapy is more precise. Especially for this disorder, ultrasonography (USG) is still the modality of choice in early detection (screening). It is different from MRI, although it is a long process, these modalities can provide a more accurate morphological image. In addition, interventional radiology also plays an important role not only in terms of diagnostics but in terms of therapy, it can also be a treatment option for this disorder.
\end{abstract}

Published by IJRP.ORG. Selection and/or peer-review under responsibility of International Journal of Research Publications (IJRP.ORG)

Keywords : Imaging, Fibroid Uterine, Leiomyomas, Tumors.

\section{Introduction}

Ladies matured 50 years and over frequently present with grievances about uterine-related tumors. These benevolent tumors are affected by hormonal factors and react to estrogen and progesterone. Generally increments in size in pregnant ladies and diminishes in size after menopause. Menarche at a youthful age and weight are hazard factors for the presence of fibroids (Thomas EJ., 2006).

By and large, these tumors are asymptomatic. There are around 20-half who show clinically, for example, menorrhagia, pelvic torment, barrenness, or confusions during pregnancy. In the event that the size is sufficiently enormous, the clinical indications can be a mass impact on the encompassing organs, for example, urinary maintenance and clogging. On the off chance that this mass develops bigger, it can likewise cause hydronephrosis and gut obstacle (Thomas EJ., 2006; Baziad A., 2014).

Despite the fact that it is beginning to be relinquished, customary radiology can in any case be an alternative in identifying this issue, particularly in wellbeing offices that are a long way from metropolitan territories (Baziad A., 2014).

\section{Anatomy}

The uterus is a reproductive organ that is owned by women. The upper third of this organ is called the fundus, the middle third is called the corpus or body, while the lower third is called the cervix. The size of this 
organ changes during pregnancy. In non-pregnant adult women, this organ measures about $7 \mathrm{~cm}$ in length, 5 $\mathrm{cm}$ in width (on the wide side) and $2.5 \mathrm{~cm}$ in diameter. The uterus is located in the pelvic cavity on the medial side, superior to the vagina, posterior to the bladder and anterior to the rectum (Bradley J, Voorhis V, 2009).

The uterine wall is formed of 3 layers, including the endometrium, myometrium and perimetrium. The endometrium is the innermost layer which is the mucosal layer consisting of columnar epithelial cells and abundant tubular glands. Myometrium is the thickest layer, located in the middle, which is the muscular layer consisting of thick-smooth muscle fibers in a longitudinal, circular and spiral pattern connected by connective tissue. During the menstrual cycle and during pregnancy, the endometrium and myometrium change extensively. The perimetrium is the serous layer that is outermost and forms the cervix in this organ (Bradley J, Voorhis V, 2009).

\section{Etiology}

Until now, the exact cause of leiomyoma uteri is not known and it is suspected as a multifactorial disease. It is believed that myoma is a monoclonal tumor resulting from a somatic mutation of a single neoplastic cell. Tumor cells have arm chromosome abnormality 12q13-15. Mutation in MED12 and HMGA2 genes also contribute etiology of fibroid. The factors that affect tumor growth, in addition to genetic predisposing factors, include estrogen, progesterone and human growth hormone (Schwartz MS, 2009; Williams, 2017).

Because the growth is hormonal, this leiomyoma does not appear until a woman has had her first menstruation (mearche) and usually decreases in size after menopause. Their size and morphology can increase suddenly during pregnancy or if the patient is taking hormonal contraceptives (Moore, Keith L, 2006).

\section{Pathophysiology}

Classification of uterine fibroids based on the location of appearance, including intraeuterine and extrauterine. Especially for intra-uterine, it is further divided into submucosal, intramural, and subserosa. Large fibroids can degenerate along with the inability of blood vessels to supply blood to the mass (Silberzweig, 2016).

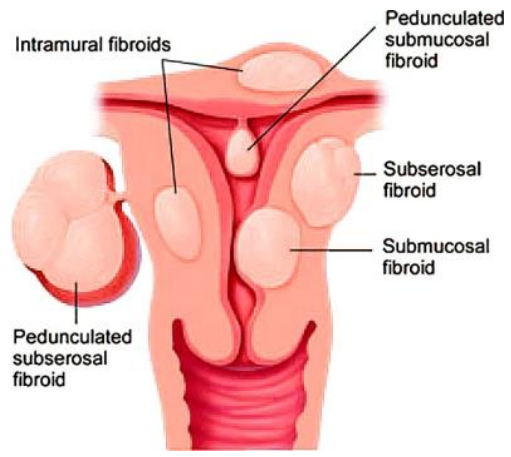

Figure 1. Illustration of the location of the appearance of fibroids which can occur intramucosa, intramural and subserosa. Specifically the submucosal and subserous types can have a stalk (pedunculated) (Campbell, S., Monga, A, 2000).

These lesions may appear extrauterine where there are structures with morphology resembling uterine fibroids in an unusual location. Based on this, the division includes parasitic leiomyoma, intravenous leiomyomatosis, disseminated peritoneal leiomyomatosis, and benign metastasizing leiomyoma (Campbell, S., Monga, A, 2000; DeCherney, A.H., Nathan, L, 2003). 
Apart from their appearance, uterine fibroids are further classified into several types according to their degeneration. There are various types of degeneration which have different characteristics on the imaging. There are 5 divisions of types of degeneration, namely (DeCherney, A.H., Nathan, L, 2003) :

- Hyaline Degeneration

This type is the most common in which $60 \%$ of uterine fibroids have a type of hyaline degeneration. This process is liquefication where initially the solid consistency changes to semisolid to large cystic containing protein components and homogeneous eosinophil cells.

- Cystic Degeneration

Apart from what is mentioned in hyaline degeneration, the process that can occur is collagen deposition. In this process, the collagen tissue in uterine smooth muscle undergoes dilution (liquefication) and settles (deposition). Due to this deposition, the structure of the lesion which should be solid becomes a sequele of edematous cystic structures with acellular centration. This type of degeneration is quite rare and only $4 \%$ of uterine fibroids have this degeneration.

- Myxoid Degeneration

The appearance of myxoid degeneration can be in the form of a soft mucoid area which is usually followed by several surrounding cystic lesions. However, this degeneration should be watched out for because it can be seen in leiomyosarcoma and other malignant lesions.

- Fatty Degeneration

As the name implies, or so-called lipoleiomyoma, where smooth muscle tissue degenerates into adipose mature tissue. This type is also rare and only about $0.02-0.3 \%$ and occurs a lot in women who have menopause.

\section{- Red Degeneration}

Red degeneration, or also known as carneous degeneration, is a process of hemorrhage infarction in the uterine fibroid tissue wherein the progression of the lesion can cause obstruction in the draining vein at the edges. This process can lead to extensive coagulation necrosis, especially common in uterine fibroid patients who are pregnant or taking oral contraceptives.

Although it is said to be benign (benign), these fibroids can transform into malignant (malignant) called leiomyosarcoma. Most of these leiyomyosarcomas occur de novo. Although the percentage of emergence is small, this transformation needs to be taken into consideration, especially since its size has progressive enlargement and degeneration in the form of cystic mixed myxoid, diagnosis varian leiomioma ini biasanya dilakukan pasca operasi pada pemeriksaan patologis dan bukan secara imaging (DeCherney, A.H., Nathan, L, 2003; Howkin's \& Bourne, 2015; Ling, F. W., Duff, P, 2001).

\section{Conventional Radiographic Depictions}

\subsection{Plain photos}

The usual sign on this examination is the presence of a groundglass image (Figure 2) in the pelvic cavity wherein the distribution of intestinal gas shadows in the pelvic cavity appears minimal or absent. This shadow can extend into the abdominal cavity depending on the size of the mass itself. Because of the extension of the mass, the intestinal gas shadow may be pushed superiorly or laterally away from the midline depending on the direction of mass extension. The morphology that can be visualized on conventional radiology is calcification in the form of popcorn-like.(Zulfiqar, 2020) 


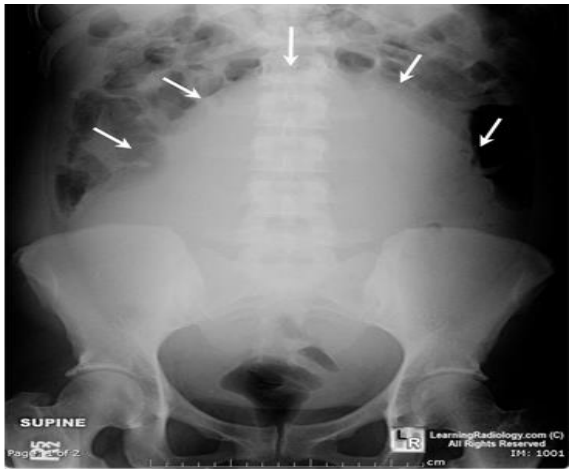

Figure 2. Plain abdominal radiograph shows a groundglass appereance with extension from the pelvic cavity to the abdomen with a superior displacement of bowel gas shadows (Hanifa, W., 1999).

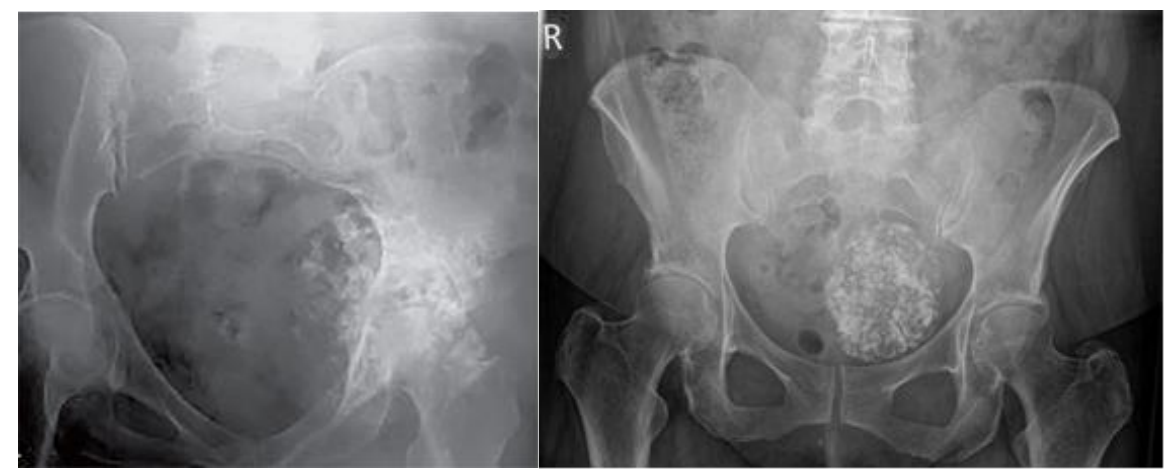

Figure 3. (a) Plain radiograph of a 58-year-old female patient diagnosed with uterine fibroids with sacral pain showing superimposed radioopaque image on the left hip. (b) Female patient aged 70 years with plain abdominal radiograph in the form of radioopaque image in the form of pop-corn calcification in the left pelvic cavity (Cicinelli E, et.al., 1995).

\subsection{Photos with contrast}

A hysterosalphingogram (HSG) is usually performed to assess tubal patency in patients with infertility. However, it is also useful for evaluating the contours of the endometrial cavity, and submucosal fibroids may present as filling defects. Sometimes submucous fibroids can cause tubal obstruction (Cicinelli E, et. al., 1995).

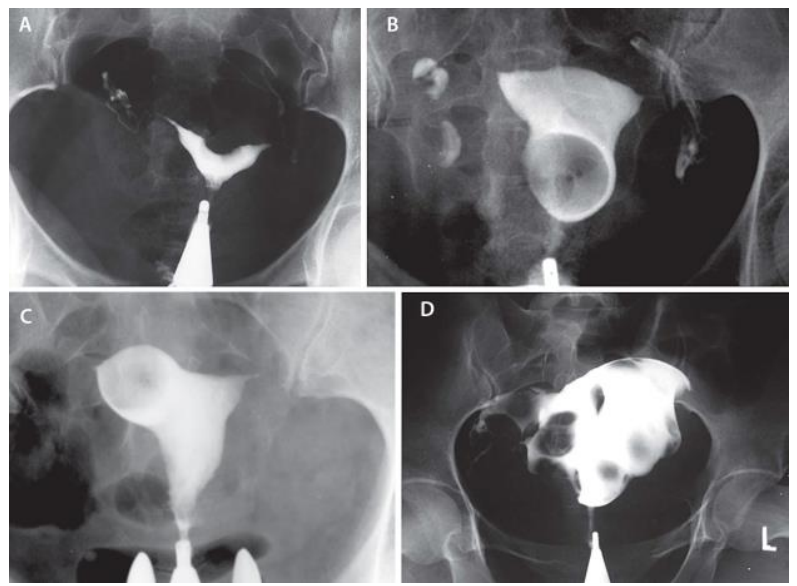


Figure 4. Variations in HSG features in patients diagnosed with leiomyoma in the submucosa area. (a) filling defect in the roof area of the endometrial cavity. (b) filling defect in the lower uterine segment causing cavity distortion. (c) A filling defect in the area of the right horn causes asymmetry in the right and left hornbones of the endometrial cavity. (d) Multiple filling defects accompanied by enlargement and distortion of the undometrial cavity (Cicinelli E, et. al., 1995).

Although difficult to see, visualization of intramural or subserous fibroids can include displacement, rotation, distortion, and enlargement of the endometrial cavity. Large lesions can also cause hypotony of the uterine muscles resulting in enlargement of the endometrial cavity. Usually, filling the contrast in the cavity to the fallopian tube requires about $6 \mathrm{cc}$. However, if it is more than that it is likely that there will be pathological enlargement of the endometrial cavity (Cicinelli E, et.al., 1995).
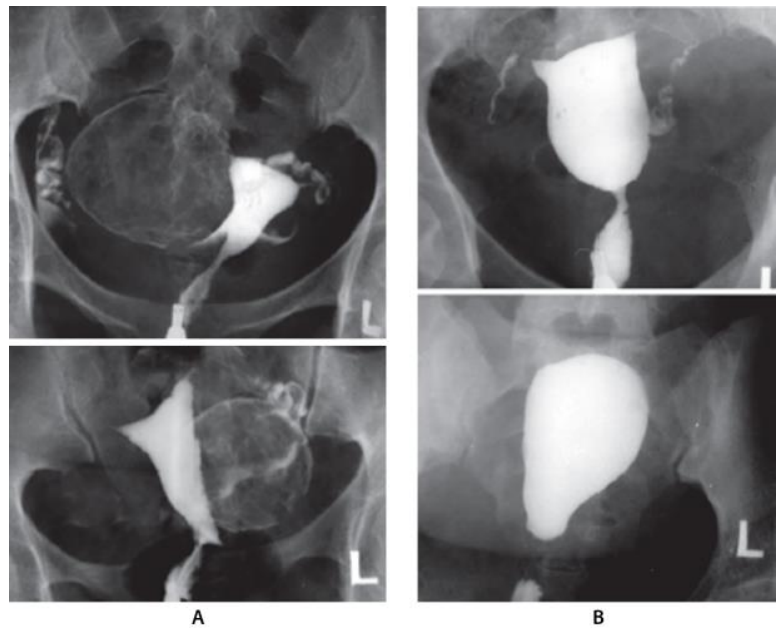

Figure 5. (a) Dislpacement of the endometrial cavity to those caused by pressure from calcified subserous uterine fibroids. (b) There is enlargement of the endometrial cavity wherein the contrast is filled to $15 \mathrm{cc}$. This indicates hypotony due to intramural fibroids (Cicinelli E, et. al. 1995).

\subsection{USG}

Trans-Abdominal Ultrasound (TAUS) and Trans-Vaginal Ultrasound (TVUS) are methods that can be used in evaluating fibroids and Ultrasound is very operator dependent

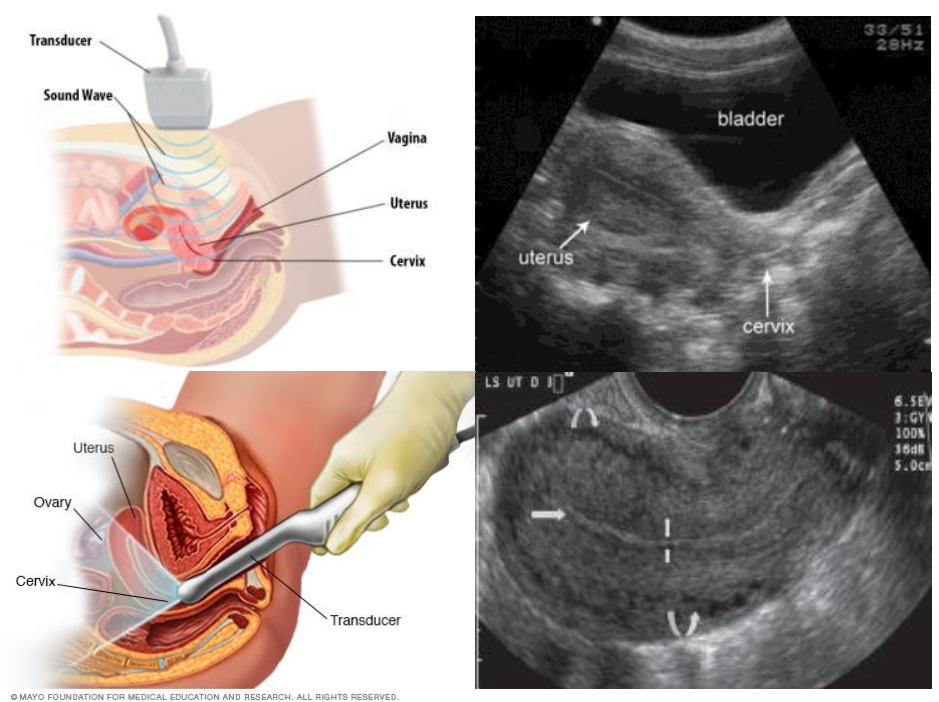


Figure 6. Ilsutration of different images produced Trans-abdominal (TAUS) and Trans-vaginal (TVUS) ultrasound of the uterus (Leibsohn S., et.al. 1990).

The profile of the uterine fibroids most often visualized (conventional type) on this ultrasound examination is a solid, well-defined, and hypoechoic mass. It should be noted that these fibroid lesions in the uterus can have a high density so that the penetration of sound waves can be obstructed as indicated by the presence of posterior shadowing which interferes with the ultrasound course so that most of them show posterior acoustic shadows even though the lesions are without calcification (Mark AS, et.al., 1987; Rashid, et al., 2016)

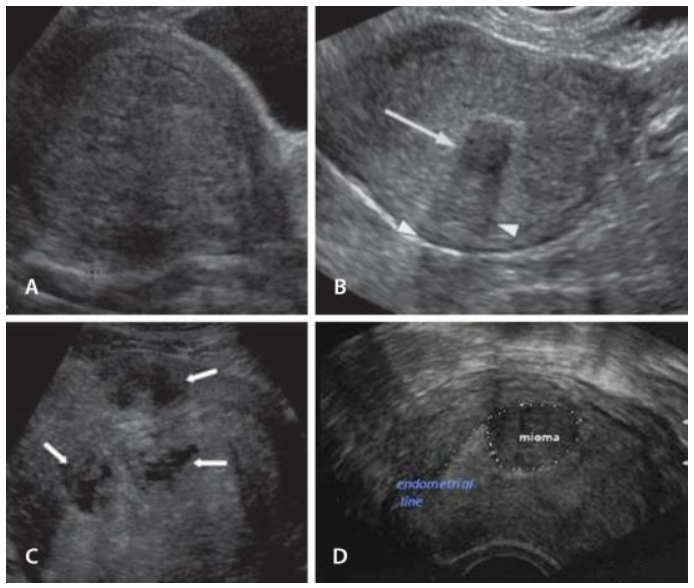

Figure 7. Ultrasound examination of the pelvis where an enlarged uterus can be obtained. (a) lesion with posterior shadowing. (b) multiple necrosis components. (c) insistence on the endometrial line. (d) may be a sign of uterine fibroids (Leibsohn S., et. al., 1990).
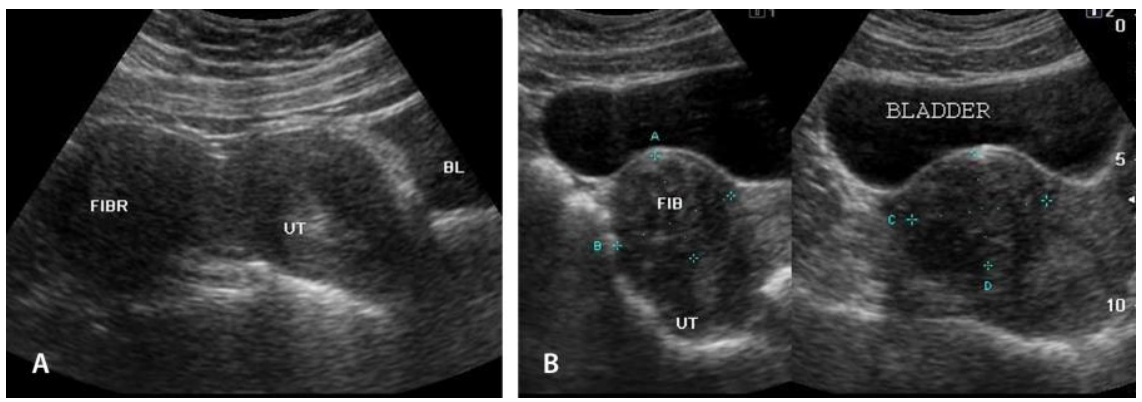

Figure 8. (a) subserous uterine fibroid, pedunculated type where heteroechoic lesions are visible that are connected to the uterine fundus. (b) intramural uterine fibroids extending to subserosa (Leibsohn S., et. al., 1990).

Doppler mapping can be useful for showing the vascular pattern of uterine fibroids. In general, these lesions have varying peripheral blood supply, some fibroids are more vascular than others. Peripheral vascularization is almost certainly found on this Doppler ultrasound, although no vascularity is also common. 

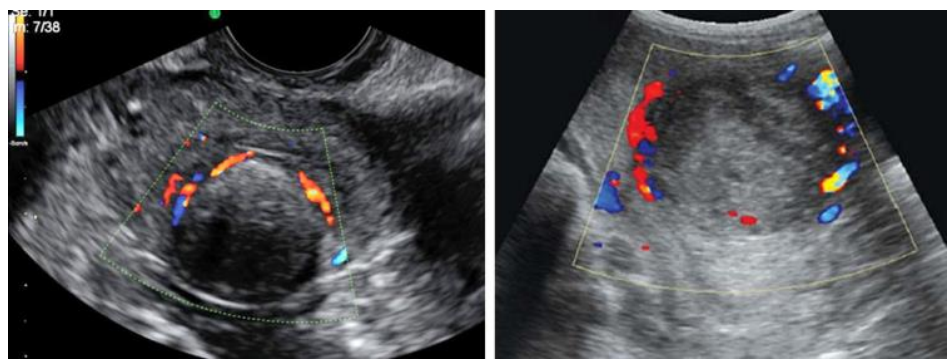

Figure 9. Doppler ultrasound of uterine fibroid lesions showing perilessal vascularization commonly seen in uterine fibroids (Mark AS., et. al., 1987).

\subsection{CT Scan}

Characteristics of abnormalities that can be found on this examination are divided into 5 types, including enlarged uterus with deformed forms, solid and cystic degeneration, calcification, infection and necrosis, and sarcomatous degeneration (Beck, W.W., 1997; Mark AS., et. al., 1987). Uterine enlargement with deformed shape is the most frequently seen finding on CT scan (image). The consistency can be solid to cystic, but it is common to find a solid with almost the same attenuation as the uterus. Cystic degeneration is common when the solid size of the tumor is large enough. Minimal enlargement of the uterus cannot be used as a criterion for this abnormality. The deformity is often found in the fundus and may appear as an intracavity mass which ligates the endometrial cavity (Prayson RA, Hart WR., 1995).

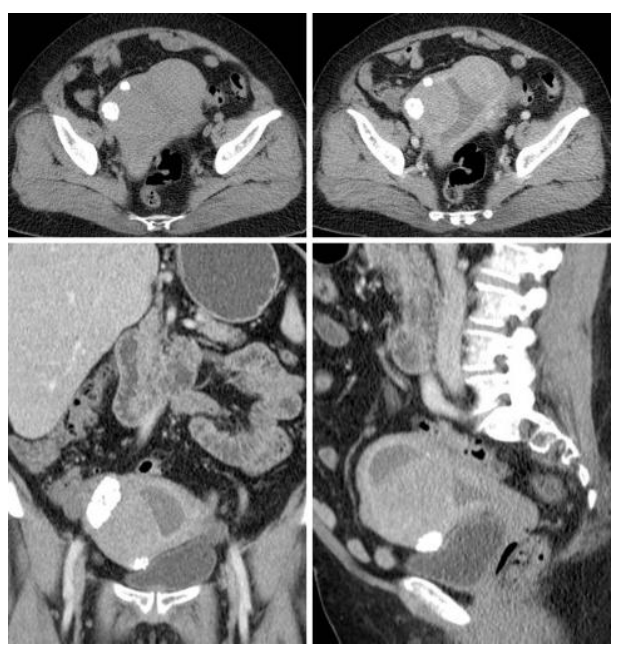

Figure 10. Multiplanar imaging CT scan of the abdomen without and with contrast in a 40-year-old woman whose uterus was enlarged with condor deformity and distortion of her endometrial cavity. Multiple intralesional calcifications also appear (Prayson RA, Hart WR., 1995).
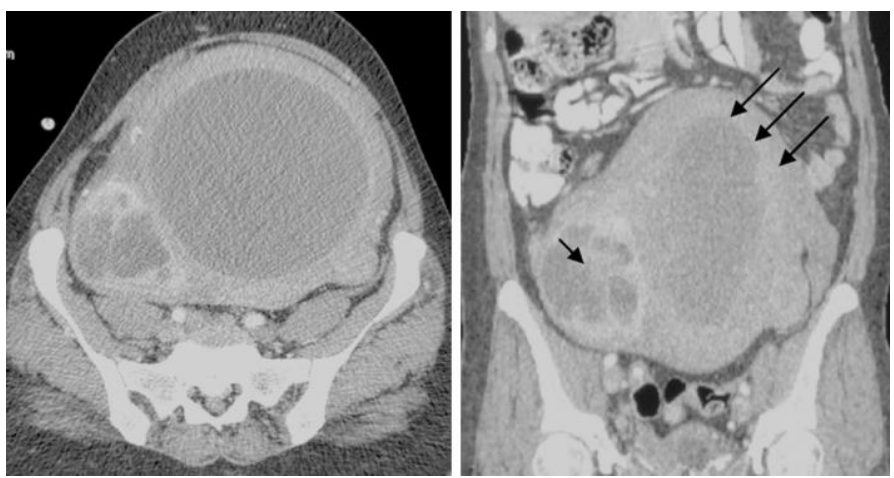
Figure 11. Axial and coronal section CT scan of the abdomen with contrast in a 34 year old woman with clinically distended abdominal. The arrows indicate the presence of rim enhancement with a semisolid lesion and a necrotic component therein. Histopathologic confirmation indicated hyalinization and infection of uterine fibroids. In addition, it was found that there was a hydrometra (Prayson RA, Hart WR., 1995).

\subsection{MRI}

Submucosal, intramural and subserous myomas are usually easily distinguished by MRI, and can diagnose myomas as small as $5 \mathrm{~mm}$. Myomas in relatively unusual locations, such as in the cervix, can also be identified. In T2WI, the normal endometrium provides hyperintense attenuation. The surrounding endometrium provides lower attenuation than the endometrium known as the junctional zone, which is the inner myometrium. The latter portion of the myometrium provides isointense attenuation at T2WI (Evans, et.al., 2007). Myomas may show degeneration due to inadequate blood supply and then have a variable and often heterogeneous appearance, which on contrast provides minimal or heterogeneous enhancement. Areas of calcification can show up as a picture of flow voids on MRI (Ilustrated Gynecology and Infertility Ultrasound, 2011). Basic protocol MRI is T1WI axial slices and T2WI sagittal/ oblique, axial slice to determine anatomy, characterisation, and location of fibroid, while optional sequences is T1WI fat sat, oblique coronal T2W, Gadolinium T1W and DWI to differentiate haemorrhagic lesions, relationship to uterine cavity or ovarian origin, and atypical leiomyomas (KubicHuch RA, et al., 2018)

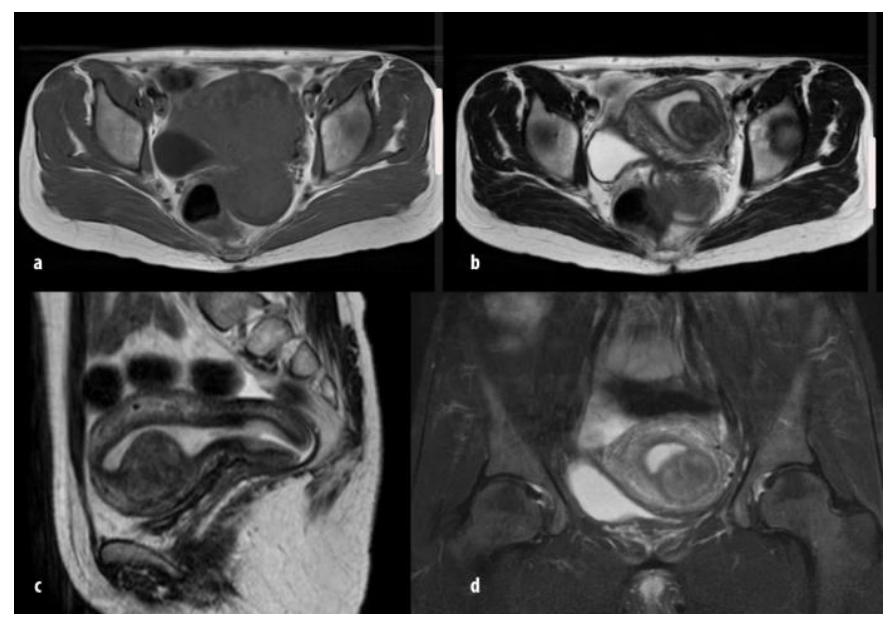

Figure 12. Classic MRI features of submucosal uterine fibroids (a) T1WI axial sequence cut. (b) T2WI axial sequence cut. (c) a cut of the T2WI Sagittal sequence. (d) cut coronal sequence T2 Fatsat. On this MRI examination of the pelvis there was an intrauterine lesion, well defined, regular edge with a submucosal location on the anterior left mid-uterine side. The lesion appears to indent the endometrial cavity. There is no parametric extension (Prayson RA, Hart WR., 1995).

Degeneration of uterine fibroids can best be seen on this MRI of the pelvis. Hyaline degeneration provides heterointense image on $\mathrm{T} 2 \mathrm{WI}$, whereas on contrast administration there is no visible enhancement. Meanwhile, cystic degeneration can give a picture like cystic lesions which on T1WI appear hypointense and T2WI appear hyperintense. For mixoid degeneration, the lesion can appear septic and red degeneration can show hypervascular lesions at the edges (Prayson RA, Hart WR., 1995). 



Figure 13. MRI of the sagittal pelvis where hyaline degeneration uterine fibroids appear as lesions of heterogeneous intensity (Moore, Keith L., 2007).
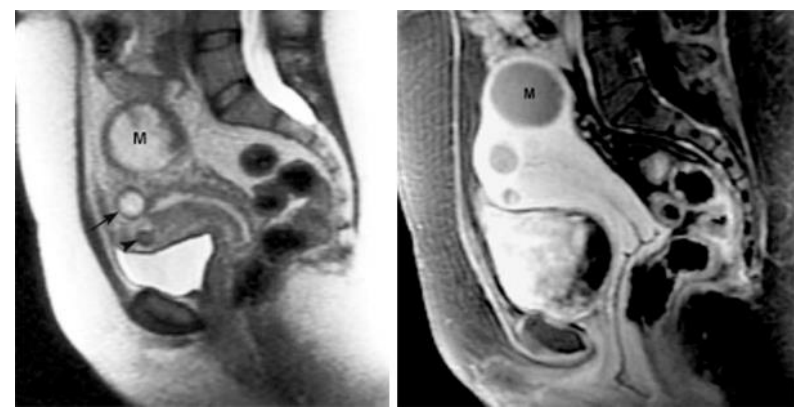

Figure 14. MRI of the axial pelvis in the TIWI and T2WI sequences shows cystic lesions with hypointense on T1WI and hyperintense on T2WI, representing multiple uterine fibroids with cystic degeneration (Moore, Keith L., 2007).

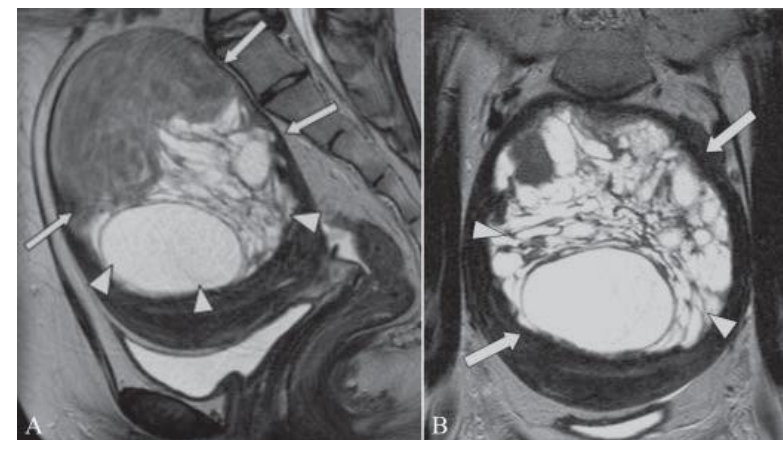

Figure 15. (a) A 21 year old woman with menorrhagia and pelvic mass. MRI examination of the Sagittal cut pelvis. (b) T2W MRI shows large large intramural fibroids (arrows) that are septated (arrows) The patient underwent myomectomy and histopathology revealed a uterine fibroid with myxoid degeneration (Moore, Keith L., 2007). 

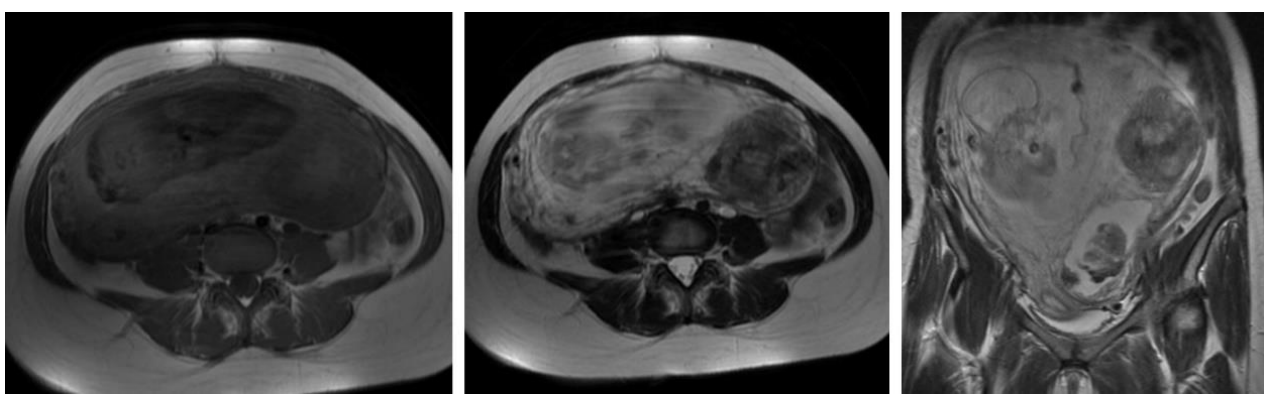

Figure 16. Pelvic MRI in gravid patients where uterine fibroids are seen with red degeneration where the lesions appear hyperintense on T1WI and hypointense on T2WI indicating increased vascularity in the lesions (Prayson RA, Hart WR., 1995; Silberzweig JE et.al., 2016).

\section{Differential Diagnosis}

\subsection{Leiomyosarcoma}

Leiomiosarcomas sometimes originate from a pre-existing myoma but are usually known to occur de novo. The classic feature of this leiomyosarcoma is a pelvic mass characterized by rapid growth in size. Leiomyosarcoma is usually a large heterogeneous mass containing a bleeding area. In contrast, this mass gives an irregular shape and has irregular margins compared to uterine myomas (Campbell, S., Monga, A., 2003).

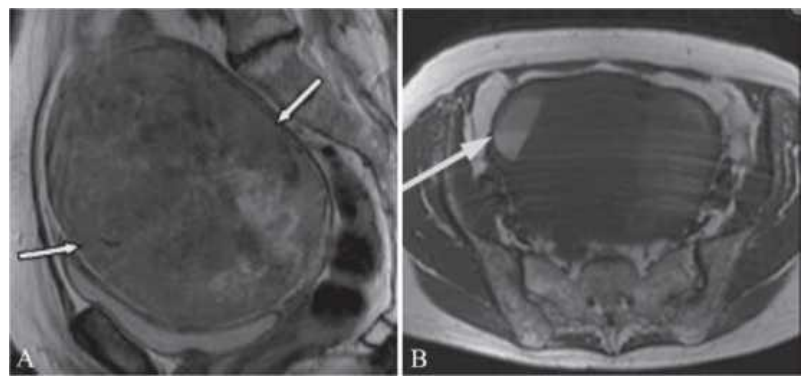

Figure 17. MRI of the sagittal abdomen shows a mass in the pelvic cavity that gives inhomogeneous hypointense signals on T2WI and on the T1WI axial section shows a hyperintense area in the mass (Campbell, S., Monga, A., 2003).

\subsection{Adenomyosis}

Adenomyosis is usually a diffuse condition, which is seen on MRI as a thickened junctional zone. It is usually easy to distinguish from uterine myomas as adenomyosis wherein adenomyosis usually has multiple hyperintense foci on T2WI, which represent glandular structures. However, sometimes adenomyosis presents as a focal mass and can then be mistaken for a myoma. Typically, focal adenomyosis is a well-defined, oval-shaped mass giving a hypointense signal on T2W MRI, whereas myomas are usually well defined and round in shape. uterine myoma is also often accompanied by dilated blood vessels, whereas focal adenomyosis is not (Hutchins FL., 1995; Cicinelli E., et.al., 1995; Baziad A., 2014). 


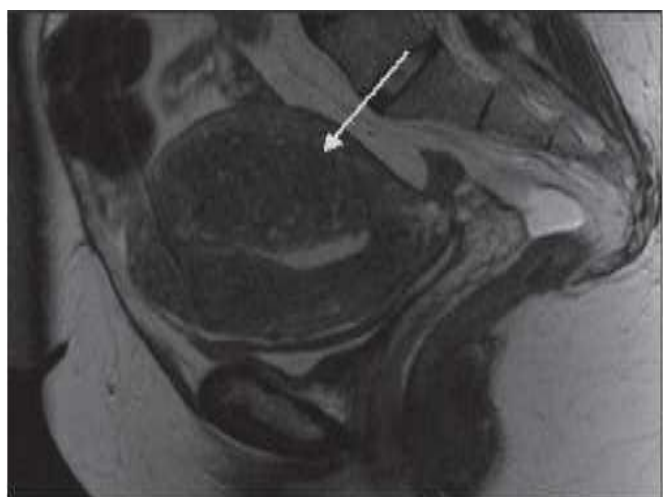

Figure 18. Sagittal T2WI cut abdominal MRI showed thickening of the junctional zone in adenomyioasis patients (Baziad A., 2014).

\subsection{Endometrial polyps}

Endometrial polyps can present with post-menopausal bleeding, but they are often an incidental finding on transvaginal ultrasound. Endometrial polyps usually present as an endometrial mass with a peduncular shape and will usually show an intact upper endometrial line. These endometrial polyps are very difficult to distinguish from submucosal myomas but sonohysteroscopy can help in the diagnosis (Baziad A., 2014).

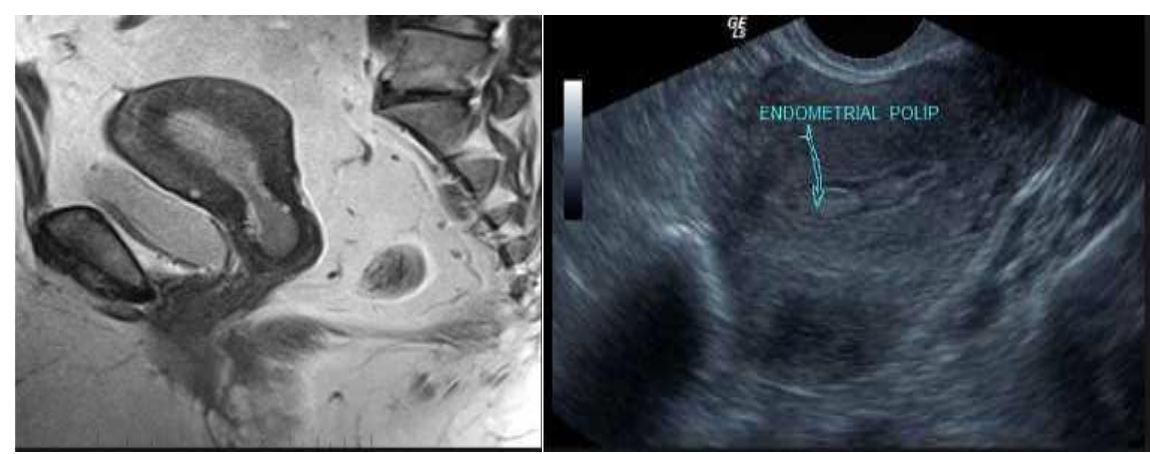

Figure 19. (a) Sagittal abdominal MRI shows hypointense image on the uterine wall on T2WI. (b) Transvaginal ultrasound shows an isochromic mass on the uterine wall (Bradley J, Voorhis V., 2009).

\section{Management}

Based on clinical practice guidelines that have been approved by the Clinical Practice Gynecology Committee, the management of uterine fibroids is divided into 4 options, including medical management, surgical management, conservative surgical thrapies and therapy with special consideration. Medical management is therapy in the form of hormonal drugs. For surgical management, the operating protocol can be either total or radical hysterectomy. Conservative surgical therapies are a method of choice for maintaining the anatomy and function of the gynecological organs. The division includes myomectomy through laparotomy incision, myomectomy through laparoscopy, hysteroscopic myomectomy, laparoscopic myolysis, and selective uterine artery embolization. As for the special consideration, this therapy is a combination of the therapies described above and prioritizes conditions outside the disease itself, such as women who are pregnant, infertile, menopausal conditions and the presence of acute bleeding. In the field of radiology the principle of management is to occlude the artery feeding the fibroid 
lesion as Conservative Surgical Therapies where the action is called selective uterine artery embolization (Hutchins FL., 1995).

The purpose of arterial occlusion is as an alternative option for female sufferers who wish to preserve the uterus, or for other considerations, such as contraindications in surgery, unsuccessful medical management, or on the basis of the choice of a patient who refuses to have surgery. In every medical action, of course, there are advantages and disadvantages. As for the advantages, namely :

- minimally invasive

- safe

- Efficacious

- Can be done on an outpatient basis

- Faster healing (usually 7-10 days the patient can return to work)

- The overall cost is relatively cheaper

As for the shortcomings, among others are :

- $10-15 \%$ do not respond to embolization

- Pelvic pain can occur up to several days after the procedure

- Premmature ovarial failure (reported in $1 \%$ of cases)

- Allergy contrast

- Leaking embolization material (rare)

The requirements in this management are :

- Age over 10 years

- Have uterine fibroids with clinical manifestations (pain, tense pelvic area, constipation, or heavy bleeding

- Have complete documentation (supporting imaging results)

- Not pregnant

- Not found malignancy (malignancy)

- Not a candidate for surgery

- Want to maintain gynecological organs

- Want to remain fertile

- There is no pelvic infection

Contraindications to this action, are :

- Active infection (PID, endometritis, abscess, etc.)

- Suspect leiomyosarcoma or other malignancy

- Have endometriosis or pelvic adhesion which can distort the anatomical location of the blood vessels

- Pregnancy

- Have immunological disorders

- The presence of coagulopathy, contrast allergy, and impaired kidney function

- Have exclusive peripheral vascular diseasel

It should be noted that this treatment is not intended to eradicate, but only to shrink the tumor (shrinkage) in the hope of reducing clinical manifestations. Of course, this needs to be a consideration in explaining to patients so that there are no misunderstandings in the future. The target is the feeding of the artery that supplies blood to the fibroid lesions. The arteries that often supply blood to fibroid lesions are the uterine arteries. However, ectopic feeding can occur if the supply from the uterine artery is inadequate to supply blood to the tumor. A commonly used emblem is Polyvinyl Alcohol (PVA), in addition to gelatine sponge embolization. (Hutchins FL., 1995, Silberzweig.,2016). 

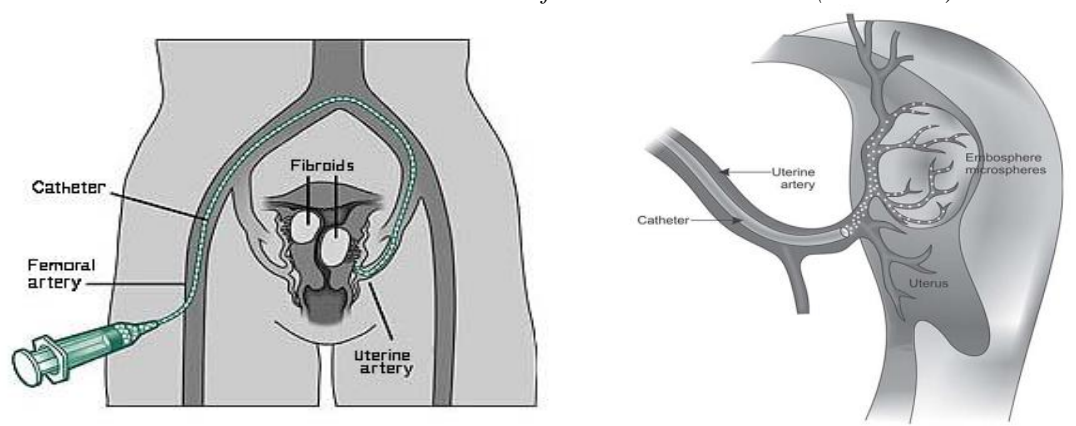

Figure 20. Illustration of selective uterine arterial embolization management in which a catheter is transarterially inserted through the femoral artery, then navigated through a. iliaca, a. ilaiaca internal branching towards a. uterine which feeds the fibroid lesions in the uterus (Hutchins FL., 1995).
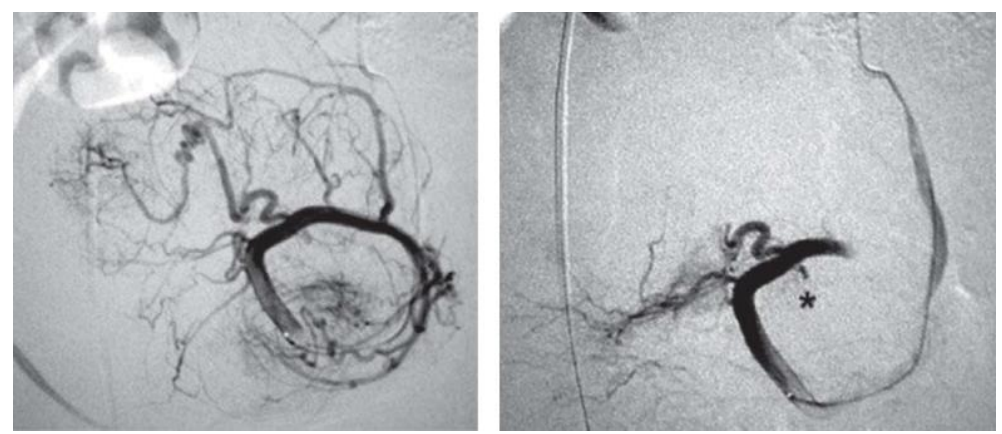

Figure 21. Digital image Subtracted Angiography (DSA) in a female patient with uterine fibroids where on the right image there is dilation with tourtousity in the uterine artery branching that supplies the fibroid lesion. The right image after injection of embolus material with the result that the artery feeding is no longer visible (Hutchins FL., 1995).

Turtousity of the arteries may prevent the catheter from entering the target lesion. In addition, vasospasm may occur during the procedure, preventing the catheter from entering the target lesion. Complications that can occur after the procedure include endometritis, tubo-ovarian or uterine abscess, amenorrhea, urinary tract infection, urinary retention, fibroid sloughing, uterine infarction. (Silberzweig.,2016) post-puncture hematoma, vomiting, temporary hypotension, bleeding, and temporary fever (Hutchins FL., 1995).

Another treatment for fibroid using FUS or high-intensity focused ultrasound (HIFU) technology. Thermal injury released by sound wave energy and vibration effect cause tissue destruction. MR-guided FUS therapy to know exact location of fibroid, with rapid gradient-echo localizer then a baseline triplanar T2-weighted image. Patient selection is similar to embolization and myomectomy, but if there is more than four fibroid, or the volume more than 500mL, are not considered (Silberzweig.,2016)

\section{Conclusion}

Radiology imaging plays an important role in diagnosing the presence of a uterine fibroid because of non-specific clinical symptoms. Clinics will almost certainly refer to radiological examinations. Plain radiographs of the abdomen and contrast studies can be the first tests in guiding the clinician to make a diagnosis. If it is not clear, advanced radiological examinations such as ultrasound, CT scan and MRI are 
the next protocols that can be done to complete the diagnosis. An understanding of the pathophysiology of uterine fibroids can certainly guide a radiologist to guide the clinician in making the correct diagnosis and management plan.

\section{References}

Baziad A. (2014). Pengobatan medikamentosa mioma uteri dengan analog GnRH. Dalam : Endokrinologi ginekologi edisi kedua. Jakarta : Media Aesculapius FKUI, 151 - 156. Diakses 6 Juli 2014. http://digilib.unsri.ac.id/jurnal/health-sciences/mioma-uteri/mrdetail/906/

Bradley J, Voorhis V. Management options for uterine fibroids, In : Marie Chesmy, Heather Whary eds. Clinical obstetric and Gynecology. Philadelphia : Lippincott Williams and Wilkins, 2009 ; $314-$ 315. Diakses 6 Juli 2014. http://digilib.unsri.ac.id/jurnal/health-sciences/mioma-uteri/mrdetail/906/

Campbell, S., Monga, (2003)A. Gynaecology by 10 Teachers. 17th Ed. P: 115 - 117

Cicinelli E, Romano F, Anastasio PS, Blasi N, Parisi C, Galantino P. (1995). Transabdominal sonohysteroscopy, transvaginal sonography and hysteroscopy in the evaluation of submucous fibroids. Obstet Gynecol. 85:42-7.

DeCherney, A.H., Nathan, L. (2003). Current Obstetri and Gynaecology Diagnosis and Therapy. McGrawHill. P: $693-699$.

Evans, Patricia., Brunsell, Susan. (2007). Uterine fibroid tumors: diagnosis and treatment. America family phycian : 75(may). p. 1503-7.

Hanifa, W. (1999). Tumor Jinak Pada Alat Genital dalam Ilmu Kandungan. Edisi III, Jakarta:Yayasan Bina Pustaka Sarwono Prawirohardjo, 338-345.

Howkin's \& Bourne. (2015). Shaw's Textbook of Gynaecology. $12^{\text {th }}$ Ed. New Delhi: B. Churchill Livingstone; $22: 275$ - 284.

Hutchins FL. (1995). Uterine fibroids diagnosis and indications for treatment. Obstet Gynecol Clin North Am; 22:659-65.

Ilustrated Gynecology and Infertility Ultrasound. Pennsylvania: National Cancer Institute [images on the internet]. (2011) [cited 2017 Jan 12]. Available from: http://www.gynaecologist4u.com/10.htm.

Kubik-Huch RA, et al.(2018).European Society of Urigenital Radiology (ESUR) Guidelines: MR Imaging of Leiomyomas. Eur Radiol:28:3125-37

Leibsohn S, d'Ablaing G, Mishell DR, Schlaerth JB. (1990). Leiomyosarcoma in a series of hysterectomies performed for presumed uterine leiomyomas. Am J Obstet Gynecol;162:968-76. 
Ling, F. W., Duff, P. (2001). Obstetri and Gynaecology Principles of Practice. McGraw-Hill; P: 1151 1172.

Mark AS, Hricak H, Heinrichs LW, Hendrickson MR, Winkler ML, Bachica JA, Stickler JE. (1987). Adenomyosis and leiomyomas: differential diagnosis with MR imaging. Radiology;163:527-9.

Moore, Keith L. (2006). Clinically Oriented Anatomy. $5^{\text {th }}$ ed. Williams \& Wilkins. Baltimore. Principles of Anatomy and Physiology. $12^{\text {th }}$ ed. Volume 2.

Novak \& Novak. (1956). Textbook of Gynaecology. $5^{\text {th }}$ Ed. The Williams \& Wilkins Company; P: $341-$ 359

Prayson RA, Hart WR. (1995). Pathologic considerations of uterine smooth muscle tumors. Obstet Gynecol Clin North Am;22:637-57.

Rashid SQ, Chou Y, Tiu C. (2016). Ultrasonography of Uterine Leiomyomas. Journal of Medical Ultrasound:24:3-12.

Silberzweig JE, Powell DK, Matsumoto AH, Spies JB. (2016). Management of Uterine Fibroid: A Focus on Uterine-sparing Interventional Techniques. Radiology:208:675-92.

Schwartz MS. (2009). Epidermiology of uterine leiomiomata. In : Chesmy M, Heather, Whary eds. Clinical Obstetric and Ginecology. Philadelphia : Lippincott Williams and Willkins; 316 - 318. Diakses 6 Juli 2014. http://digilib.unsri.ac.id/jurnal/health-sciences/mioma-uteri/mrdetail/906/

Thomas EJ. (2006). The aetiology and phatogenesis of fibroids. In : Shaw RW. eds. Advences in reproduktive endocrinology uterine fibroids. England - New Jersey : The Phartenon Publishing Group; 1 - 8. Diakses 6 Juli 2014._http://digilib.unsri.ac.id/jurnal/health-sciences/miomauteri/mrdetail/906/

Williams ARW. (2017). Uterine fibroids - what's new? F-1000Research: 6: 1-7.

Zulfiqar M, Shetty A, Tsai R, Gagnon M-H, Balfe DM, Mellnick V. (2020). Diagnostic Approach to Benign and Malignant Calcifications in the Abdomen and Pelvis. Radiographics:40:1-23. 
